\title{
TEORES DE NUTRIENTES NA FOLHA, QUALIDADE DO SUCO E MASSA SECA DE RAIZES DE LARANJA-"VALÊNCIA" EM FUNÇÃO DA IRRIGAÇÃO E FERTIRRIGAÇÃO'
}

\author{
ROBERTO LYRA VILLAS BÔAS², MARIA HELENA MORAES², JOSÉ RENATO ZANINI ${ }^{3}$, \\ LUIS CARLOS PAVANI ${ }^{3}$, DANIELA APARECIDA CAMARGO ${ }^{4}$, LUIZA HELENA DUENHAS ${ }^{5}$
}

\begin{abstract}
RESUMO - O presente trabalho foi desenvolvido na Área Experimental de Irrigação da Faculdade de Ciências Agrárias e Veterinárias de Jaboticabal/Unesp, com o objetivo de avaliar o efeito da fertirrigação sobre o teor foliar de macro e de micronutrientes, a massa fresca de raízes e a qualidade do suco de frutos em um pomar de laranja-'Valência'. Os tratamentos utilizados foram: (SI) sem irrigação e adubação com fertilizante sólido parcelado em quatro vezes; (MI-100) fertirrigação por microaspersão com 100\% da evapotranspiração; (MI-50) fertirrigação por microaspersão com $50 \%$ da evapotranspiração; (G-100) fertirrigação por gotejamento com 100\% da evapotranspiração; e (G-50) fertirrigação por gotejamento com $50 \%$ da evapotranspiração. Os teores de macro e micronutrientes nas folhas não foram alterados pela irrigação, pelos sistemas de fertirrigação e pela lâmina de água aplicada. A acidez total titulável foi superior no tratamento sem irrigação, e a \% de suco no fruto e "ratio" não foram afetadas pelos tratamentos com e sem irrigação. A massa fresca de raiz foi maior nos tratamentos irrigados, porém não foram constatadas para esse parâmetro diferenças entre os sistemas de gotejamento e microaspersão. A maior concentração de raízes ocorreu até $10 \mathrm{~cm}$ de profundidade e até $30 \mathrm{~cm}$ de distância do emissor.
\end{abstract}

Termos para Indexação: fertirrigação, irrigação, laranja, qualidade do suco.

\section{NUTRIENTS LEVELS OF LEAF, JUICE QUALITY AND ROOTS FRESH WEIGHT OF ORANGE DUE IRRIGATION AND FERTIGATION}

\begin{abstract}
The present work was developed in the Experimental Area of Irrigation of University of Agrarian and Veterinary Sciences of Jaboticabal/Unesp, with the objective of evaluating the effect of the fertigation on the foliar teor of macro and micronutrients, the fresh weight of roots and the juice quality of fruits in an orange "Valência" orchard. The used treatments were: (SI) without irrigation and manuring with solid fertilizer parceled out in four times; (MI-100) micro sprinkler fertigation with 100\% of the evapotranspiration; (MI-50) micro sprinkler fertigation with 50\% of the evapotranspiration; (G-100) drip fertigation with $100 \%$ of the evapotranspiration and (G-50) drip fertigation with $50 \%$ of the evapotranspiration. The foliar analysis showed no difference of macro and micronutrients by treatments for this parameter. Total soluble solids was higher in the treatment without irrigation, and fruit juice percent and "ratio" were not affected by treatments with and without irrigation. The fresh weight of roots was higher in the irrigated treatments, but no differences were observed between drippers and micro sprinklers treatments. The root concentration was higher at $10 \mathrm{~cm}$ deep and $30 \mathrm{~cm}$ from the emissor.
\end{abstract}

Index terms: fertigation, irrigation, orange, roots, juice quality.

\section{INTRODUÇÃO}

Nas últimas décadas, têm ocorrido consideráveis avanços no aprimoramento dos métodos de irrigação e na melhor utilização desses equipamentos. Hoje, sabe-se que o sistema de irrigação é um excelente condutor e distribuidor de qualquer produto químico ou resíduo orgânico. A adição de fertilizantes pela água de irrigação caracteriza a prática de fertirrigação (Hernandez, 1994), e a sua utilização traz uma série de vantagens para a agricultura.

Segundo Favetta (2001), entre as diversas opções de equipamentos de irrigação, a que ultimamente apresenta maior taxa de crescimento é a irrigação localizada, que engloba o gotejamento e a microaspersão.
Entre as vantagens do sistema de irrigação por gotejamento, pode-se destacar que a solução é aplicada na zona ativa das raízes, onde a água está sendo removida, as perdas de nutrientes por lixiviação são pequenas e a aplicação localizada não favorece a ocorrência de doenças foliares. Entre os cuidados que esse sistema requer, pode-se citar que as soluções ácidas aplicadas ao solo têm maior efeito negativo pelo fato de haver maior concentração em pequeno volume de solo, o mesmo ocorrendo para soluções salinas, tornando restrito o sistema radicular. O conhecimento da conformação dos bulbos para as diferentes condições de campo é muito importante para projetos de irrigação e para a prática da fertirrigação (Zanini, 1991), bem como para se obter a máxima produção por unidade de água e fertilizantes aplicados (Khan et al., 1996).

1 (Trabalho 075/2001). Recebido: 27/03/2001. Aceito para publicação: 22/10/2001.

2 Departamento de Recursos Naturais -Ciência do Solo, FCA/UNESP, Caixa Postal 237, CEP: 18603-970, Botucatu, SP. E-mail: rlvboas@fca.unesp.br 3 Departamento de Engenharia Rural, FCAV/UNESP, Campus de Jaboticabal-SP

4 Aluna do curso de Agronomia, FCA/UNESP, Campus de Botucatu-SP

5 Engenheira Agrônoma, Ms, doutoranda na ESALQ/USP, Piracicaba-SP 
Como no Brasil são poucos os trabalhos de pesquisa que abordam o efeito do manejo químico sobre as propriedades dos solos (Yamada, 1985 citado por Silva \& Justino, 1994) e o crescimento das plantas, principalmente empregando a prática da fertirrigação, torna-se oportuno que se apresentem estudos e resultados comparativos entre os meios tradicionais de adubação e a fertirrigação.

O trabalho proposto teve por objetivo avaliar o efeito da fertirrigação, realizada por seis anos consecutivos em pomar de cítrus, num Latossolo Roxo argiloso, no teor de nutrientes nas folhas, na qualidade tecnológica do suco e no desenvolvimento e distribuição do sistema radicular das plantas.

\section{MATERIAL E MÉTODOS}

O trabalho foi instalado na Área Experimental de Irrigação da Faculdade de Ciências Agrárias e Veterinárias, Câmpus de Jaboticabal/ UNESP, num Latossolo Roxo de textura muito argilosa, com variedade de laranjeira-valência enxertada em limoeiro-cravo e espaçamento entre plantas de $8 \times 5$ metros. A irrigação e a fertirrigação nos diferentes sistemas tiveram início em 1992. Na fertirrigação, foram utilizadas basicamente a uréia, o MAP e o cloreto de potássio, aplicados mensalmente. As aplicações de micronutrientes foram realizadas via foliar.

Os tratamentos empregados foram: sem irrigação (SI) e adubação utilizando fertilizante sólido, parcelado em 4 vezes; fertirrigação por microaspersão com $100 \%$ da evapotranspiração (MI-100), calculada com base na evaporação do tanque classe A e no coeficiente da cultura (ET); fertirrigação por microaspersão com $50 \%$ da ET (MI-50); fertirrigação por gotejamento com $100 \%$ da ET (G-100); fertirrigação por gotejamento com 50\% da ET (G-50). Os sistemas de irrigação por microaspersão e gotejamento empregaram um microaspersor (20 litros por hora) e quatro gotejadores por planta (15 litros por hora), respectivamente. A área molhada pelos quatro gotejadores correspondeu a $22 \%$ da área relativa ao espaçamento da cultura, enquanto para o microaspersor esta foi de $23 \%$. Este percentual corresponde aproximadamente à área mínima necessária $(20 \%)$ para regiões em que a irrigação é complementar e não obrigatória, segundo Keller \& Karmelli (1975), citados por Bernando (1995).

A parcela foi formada por quatro plantas, localizadas numa mesma linha de plantio, sendo consideradas as duas plantas centrais da área útil de amostragem.

Os tratamentos para coleta de folhas e análise da qualidade do suco foram arranjados segundo modelo de blocos ao acaso com 5 tratamentos e 4 repetições para análise química de folha e 5 repetições para análise do suco. A massa de raiz foi submetida à análise de variância segundo modelo de blocos ao acaso, em esquema fatorial $5 \times 3 \times 4$, ou seja, 5 sistemas de irrigação, 3 profundidades de amostragem, 4 distâncias do ponto de gotejamento ou da localização do microaspersor e 4 repetições.

As folhas para a análise química foram coletadas em maio de 1998, sendo que, para cada tratamento, cerca de 16 folhas foram amostradas em duas plantas da área útil da parcela. A coleta de folhas seguiu as recomendações do Grupo Paulista de Adubação e Calagem em Cítrus (1994), sendo retiradas a $3^{\mathrm{a}}$ e $4^{\mathrm{a}}$ folhas, em cada quadrante e na altura mediana da copa, a partir de frutos gerados na primavera, em ramos com frutos de até $4 \mathrm{~cm}$ de diâmetro.

As análises no suco da fruta foram realizadas no Departamento de Tecnologia e Análises da Faculdade de Ciências Agrárias e Veterinárias de Jaboticabal. Os frutos foram coletados na altura média de $1,2 \mathrm{~m}$, sendo retirados 15 frutos de cada planta da área útil da parcela, nos quatro quadrantes da planta. Os frutos foram misturados, sendo que, da amostra composta, foram selecionados 10 frutos que foram lavados e pesados.

As análises do suco foram feitas tomando-se ao acaso 5 metades superiores e 5 metades inferiores do fruto, das quais foi extraído o suco. A porcentagem do suco foi dada pela equação: $\%$ suco $=($ peso de suco/peso da amostra $) \times 100$.

As determinações de sólidos solúveis totais, expresso em ${ }^{\circ}$ Brix (SST), acidez total titulável (ATT), expresso em g de ácido cítrico/100mL e a relação SST/ATT ("Ratio") foram realizadas seguindo metodologia citada por Tressler \& Joslyn (1961).

Para a coleta de raízes, foram abertas trincheiras que se localizaram perpendicularmente à linha de plantio, em média a 1,9 $\mathrm{m}$ do tronco da planta e apresentavam as seguintes dimensões: profundidade em torno de $1,70 \mathrm{~m}$, largura de $0,80 \mathrm{~m}$ e comprimento de $1,50 \mathrm{~m}$. As trincheiras foram abertas com retroescavadeira sendo que, posteriormente, realizou-se uma uniformização das paredes do perfil, utilizando-se de pá reta e tomando-se os devidos cuidados para não causar danos às raízes.

As amostras contendo as raízes, foram coletadas nas trincheiras através da utilização de um amostrador volumétrico de aço inox de 10x10x10 cm, o qual foi cravado horizontalmente ao longo da parede das trincheiras, às profundidades de $0-10,15$ - 25, 30 - $40 \mathrm{~cm}$ e às distâncias de 30; 60; 90 e $120 \mathrm{~cm}$ a partir do centro do bulbo de molhamento.

As amostras coletadas foram secas e passadas em peneira de $2 \mathrm{~mm}$ de diâmetro. Com auxílio de uma pinça, foram coletadas as raízes que passaram pela malha da peneira. Após a separação das raízes, estas foram lavadas em água destilada, até a eliminação de todo excesso de solo. Após a lavagem, as raízes foram colocadas em frascos-estoque com capacidade de $50 \mathrm{ml}$, juntamente com álcool a $50 \%$ e, em seguida, acondicionadas em geladeira.

A determinação da massa de raízes frescas foi feita após a secagem superficial da raiz utilizando papel de filtro. Em seguida, as amostras de raízes foram secas em estufa por 72 horas a $110^{\circ} \mathrm{C}$ para a determinação da massa da matéria seca.

\section{RESULTADOS E DISCUSSÃO}

A análise dos teores de macro e micronutrientes nas folhas da planta (Tabela 1) indica que, de modo geral, os teores de N, P e K, aplicados de forma diferenciada, quando comparada à aplicação via sólida da fertirrigação, não foram afetados pelos tratamentos.

Os teores encontrados para N, P e K estão acima da faixa considerada adequada para laranja, segundo Quaggio et al. (1996), o que, possivelmente, tenha dificultado a obtenção de diferenças significativas entre os tratamentos. Já para o Ca, em todos os tratamentos, os valores encontrados nas folhas são considerados abaixo do ideal. Rego (1997) obteve resultado semelhante de redução do teor de Ca com aumento do teor foliar 
de $\mathrm{K}$, atribuindo este aspecto à inibição do $\mathrm{K}$ no processo de absorção de Ca pela planta.

A significância a 5\%, determinada pelo teste $\mathrm{F}$, para o nitrogênio, não foi confirmada pelo teste de comparação de médias (Tukey), sendo que os valores médios obtidos foram semelhantes.

Os teores de manganês, para os tratamentos com microaspersão 50 e 100\%, foram iguais e diferiram do tratamento sem irrigação, embora os valores encontrados $\left(33 \mathrm{~g} \mathrm{~kg}^{-1}\right)$ estejam próximos do limite da faixa considerada adequada por Quaggio et al. (1996), que é de $35-300 \mathrm{~g} \mathrm{~kg}^{-1}$.

Para os teores de Mn na folha, era de se esperar resultados diferentes dos obtidos nesse experimento, uma vez que a disponibilidade de Mn no solo aumenta com o decréscimo do potencial redox (Borket, 1991), que pode ocorrer em situação de solo úmido, principalmente próximo à superfície do solo, na região do bulbo molhado.

Os resultados de teor foliar indicam que os tratamentos, de modo geral, não influenciaram o estado nutricional das plantas, porém, deve-se destacar que, apesar disso, os tratamentos irrigados produziram em média, em 1998 , cerca de $72 \%$ a mais que o SI. Considerando a média de 2 anos (1997 e 1998), essa diferença foi de $51 \%$. Por isso, os teores foliares, em função de indicar um valor relativo $\left(\mathrm{g} \mathrm{kg}^{-1}\right)$, podem não caracterizar adequadamente as diferenças entre os tratamentos, uma vez que as plantas que tiveram um desenvolvimento menor, podem até apresentar teores de nutrientes nas folhas maiores em relação às que desenvolveram mais e tiveram os nutrientes absorvidos diluídos em uma massa seca maior. Pode-se também sugerir que a translocação dos nutrientes, considerando a época da coleta das folhas, tenha sido preferencialmente para os frutos. Essa hipótese tem apoio no trabalho de Legaz \& Primo-Millo (1988), que estudaram o destino do nitrogênio proveniente de fertilizantes marcados e aplicados através da fertirrigação em pomar adulto de laranja"Valência" e relataram que o fruto foi o único órgão que acumulou nitrogênio marcado e não marcado incorporado em compostos solúveis.

As análises no fruto (Tabela 2) indicam que a $\%$ de suco, a SST e a ATT foram influenciadas significativamente pelos tratamentos. A \% de suco no fruto, apesar de não diferir significativamente pelo teste de comparação de médias (Tukey), pelo teste $\mathrm{F}$, apresentou resultado altamente significativo e, portanto, aceita-se como comprovado que há diferenças reais, não casuais, entre as médias.

A maior lâmina de água aplicada nos tratamentos com $100 \%$ da ET não influenciou significativamente esse parâmetro, o mesmo ocorrendo para os tratamentos irrigados em relação ao SI. No entanto, pode-se justificar esse resultado em função de a porcentagem de suco ser um valor que expressa um dado relativo, ou seja, se os tratamentos irrigados aumentaram o número de frutos por planta ou mesmo o tamanho de fruto em relação ao SI, esse aumento foi proporcional tanto na casca como no suco; no entanto, como já citado anteriormente, a produtividade foi diferente entre os tratamentos irrigados em relação ao sem irrigação.

Ragoso (1999), estudando o efeito da fertirrigação comparada com o uso de adubo aplicado de forma sólida, em "Valência" enxertada em tangerina-"Cleópatra", não obteve diferenças entre os tratamentos para \% de suco, atribuindo esse efeito à boa distribuição de chuva durante o experimento.

A SST, expressa em ${ }^{\circ}$ Brix, mostrou ser diferente significativamente entre os tratamentos M-100\% e SI. Os frutos no tratamento $\mathrm{M}-100 \%$ apresentaram em média tamanho de 7,9 $\mathrm{cm}$ (média entre diâmetro e altura dos frutos) e no SI, de 7,3 cm. Essa diferença de tamanho justifica os resultados encontrados para a SST, uma vez que, nos frutos menores, houve menor diluição dos sólidos solúveis totais. Além disso, segundo Bergman (1992), o manganês está direta e indiretamente relacionado com a fotossíntese e, portanto, o baixo teor desse elemento é acompanhado pela redução dos teores de açúcares e celulose.

Para a ATT, maiores valores foram obtidos no tratamento SI em relação aos demais irrigados. Dentre os nutrientes determinados na folha da planta, o Mn foi o único que diferiu estatisticamente entre os tratamentos. Por isso, tentou-se uma correlação entre os resultados de teor de Mn na folha e a ATT. Obteve-se uma correlação positiva com um coeficiente de correlação de 0,57 , significativo pelo teste ta $5 \%$ de probabilidade.

A "ratio", apesar de não apresentar diferenças significativas, foi mais baixa no SI em relação aos demais tratamentos. Para este parâmetro, também se obteve correlação entre teor de Mn na folha e "ratio", porém negativa, significativa para teste t a $1 \%$ e com um $r=-0,67$.

Comparando gotejamento e microaspersão em pomar de laranja- "Shamouti", não se obteve diferença de qualidade do fruto, porém encontrou diferença de produtividade, sendo esta maior no tratamento com gotejamento.

Os resultados das análises das características tecnológicas do suco nos tratamentos irrigados, encontrados nesse trabalho, aproximam-se dos citados por Figueiredo (1991) no que se refere à $\%$ de suco $(50 \%)$, porém são mais baixos em relação aos teores médios de Brix $(11,8 \%)$, acidez $(1,05)$ e "ratio" $(11,2 \%)$.

Na Tabela 3, são apresentados os resultados de massa fresca de raízes considerando os fatores de variação: irrigação, profundidade de amostragem e distância do ponto de emissão. Os resultados foram apresentados de forma separada para cada fator, uma vez que, na análise estatística, o teste $\mathrm{F}$ foi significativo a $1 \%$ para os fatores individualmente e para a interação profundidade e posição de amostragem.

Nota-se que os sistemas de irrigação G-100, G-50 e M100 apresentaram um sistema radicular significativamente diferente em relação ao tratamento SI, e dentre os tratamentos irrigados, o M-50 não diferiu em relação ao SI. O sistema radicular, considerando apenas o sistema de irrigação, foi bastante variável segundo a lâmina de água aplicada; no entanto, praticamente não variou para uma mesma lâmina entre a aplicação via gotejamento em relação à microaspersão.

Considerando a variação da massa de raiz em relação ao ponto de emissão de água (distância horizontal), verifica-se que, a partir da amostragem aos $60 \mathrm{~cm}$, os valores de massa de raízes foram semelhantes e não diferiram estatisticamente entre si. Tal fato indica que a quantidade de raízes diminuiu com o aumento da distância do tronco, corroborando os resultados obtidos por Avilán et al. (1982) e Pace \& Araújo (1986), os quais detectaram maior concentração de raízes dentro da copa das árvores, diminuindo com a distância do tronco.

Apesar de a microaspersão distribuir a água por uma área maior no solo, em relação ao gotejamento, não se constatou 
TABELA 1 - Teores médios de nutrientes em folhas de laranjeira-'Valência’ em função dos tratamentos.

\begin{tabular}{|c|c|c|c|c|c|c|c|c|c|c|c|c|}
\hline Tratam entos & $\mathrm{N}$ & $\mathrm{P}$ & K & $\mathrm{C}$ a & $\mathrm{Mg}$ & S & B & $\mathrm{C} \mathrm{u}$ & $\mathrm{Fe}$ & & $\mathrm{Mn}$ & $\mathrm{Zn}$ \\
\hline & $\cdots$ & $-\cdots$ & --- & $\mathrm{k} \mathrm{g}^{-}$ & $-\cdots$ & $-\cdots$ & $-\cdots$ & $\cdots$ & $\mathrm{mg} \mathrm{k}$ & $b^{-1}$ & $\cdots$ & $\cdots$ \\
\hline S I & 29 & 1,5 & 19 & 29 & 3,3 & 2,3 & 78 & 10 & 129 & 58 & $\mathrm{a}$ & 16 \\
\hline$G-100$ & 29 & 1,9 & 19 & 29 & 3,4 & 2,3 & 78 & 7 & 136 & 39 & $a b$ & 16 \\
\hline$G-50$ & 26 & 1,6 & 18 & 28 & 3,2 & 2,4 & 76 & 7 & 141 & 45 & $\mathrm{ab}$ & 21 \\
\hline$M-100$ & 30 & 1,7 & 18 & 27 & 3,1 & 2,4 & 80 & 9 & 143 & 33 & $\mathrm{~b}$ & 18 \\
\hline$M-50$ & 29 & 1,7 & 18 & 29 & 3,1 & 2,2 & 85 & 6 & 110 & 33 & $\mathrm{~b}$ & 15 \\
\hline $\mathrm{F}$ & * & $\mathrm{n} \mathrm{s}$ & $\mathrm{n} \mathrm{s}$ & $\mathrm{n} \mathrm{s}$ & $\mathrm{n} \mathrm{s}$ & $\mathrm{n} \mathrm{s}$ & $\mathrm{N} \mathrm{s}$ & $\mathrm{n} \mathrm{s}$ & $\mathrm{n} \mathrm{s}$ & & $* *$ & $\mathrm{n} \mathrm{s}$ \\
\hline $\mathrm{C} V \cdot(\%)$ & 3 & 10 & 6 & 10 & 7 & 7 & 8 & 39 & 14 & & 20 & 20 \\
\hline
\end{tabular}

Médias seguidas das mesmas letras ou sem letras não diferem estatisticamente entre si (Tukey a 5\%).

ns= não significativo, * significativo a $5 \%, * *$ significativo a $1 \%$. SI= sem irrigação; G-100 e G50= Gotejamento com 100 e $50 \%$ da evapotranspiração (ET); M-100 e M-50= Microaspersão com 100 e 50\% da ET.

TABELA 2 - Valores médios das análises tecnológicas do suco de frutos de laranja- 'Valência' em função dos tratamentos.

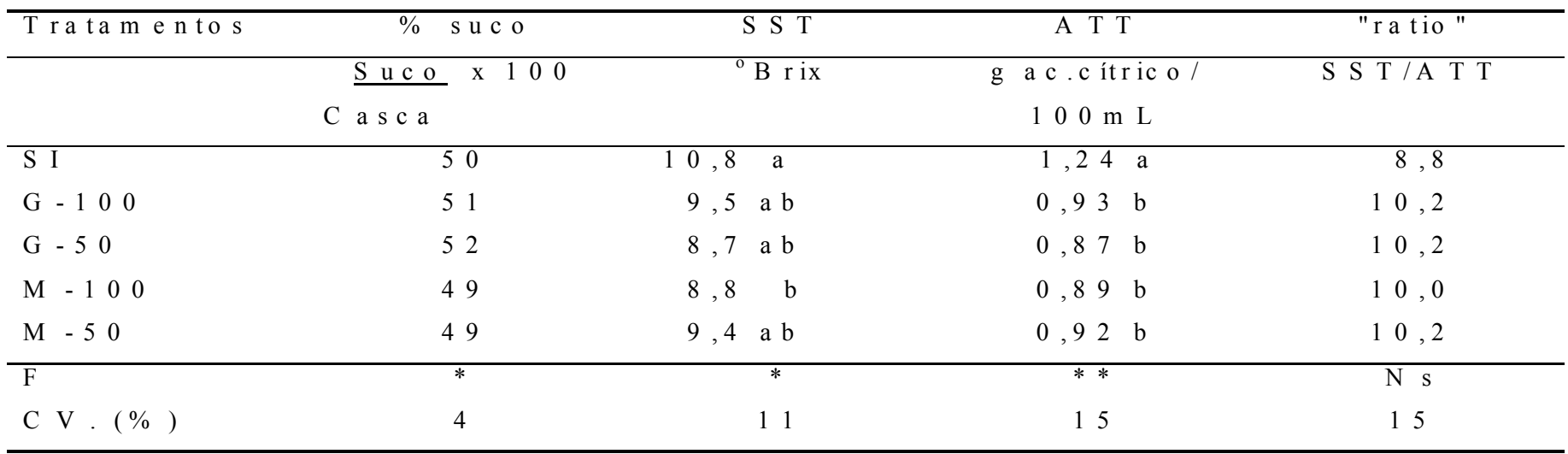

Médias seguidas das mesmas letras ou sem letras não diferem estatisticamente entre si (Tukey a 5\%).

ns= não significativo, * significativo a $5 \%$,** significativo a $1 \%$. SI= sem irrigação; G-100 e G50= Gotejamento com 100 e $50 \%$ da evapotranspiração (ET); M-100 e M-50= Microaspersão com 100 e 50\% da ET.

TABELA 3 - Massa fresca de raízes (gramas/L de solo) em função dos fatores de variação considerados individualmente.

\begin{tabular}{|c|c|c|c|c|c|}
\hline Tratamentos & raiz (g) & $\begin{array}{c}\text { D istância } \\
\text { horizontal }(\mathrm{cm})\end{array}$ & Raiz (g) & $\begin{array}{c}\text { Profundidade } \\
(\mathrm{cm})\end{array}$ & raiz $(g)$ \\
\hline SI & $0,326 \mathrm{~b}$ & 30 & $1,265 \mathrm{a}$ & $0-10$ & $1,137 \mathrm{a}$ \\
\hline$G-100$ & $1,071 \mathrm{a}$ & 60 & $0,726 \mathrm{~b}$ & $15-25$ & $0,567 \mathrm{~b}$ \\
\hline$G-50$ & $0,860 \mathrm{a}$ & 90 & $0,682 \mathrm{~b}$ & $30-40$ & $0,719 \mathrm{~b}$ \\
\hline$M-100$ & $1,040 \mathrm{a}$ & 120 & $0,559 \mathrm{~b}$ & & \\
\hline M -50 & $0,741 \mathrm{ab}$ & & & & \\
\hline Total & - & & 3,232 & & 2,423 \\
\hline $\mathrm{F}$ & $* *$ & & $* *$ & & $* *$ \\
\hline
\end{tabular}

Médias seguidas das mesmas letras ou sem letras não diferem estatisticamente entre si (Tukey a 5\%).

$\mathrm{ns}=$ não significativo, * significativo a $5 \%, * *$ significativo a $1 \%$. SI= sem irrigação; G-100 e G50= Gotejamento com 100 e $50 \%$ da evapotranspiração (ET); M-100 e M-50= Microaspersão com 100 e 50\% da ET.

interação significativa para massa fresca de raízes entre sistema de irrigação e distância do ponto de emissão. Uma possível explicação para o ocorrido é que a linha contendo os gotejadores não se encontrava fixada ao solo, e principalmente quando foram realizadas as capinas, a posição da mesma pode ter sido alterada. Já os microaspersores também podem ter modificado a sua área de molhamento em função do crescimento de galhos na parte inferior da copa que impediram a distribuição homogênea da água na superfície do solo e, portanto, possivelmente, a água não atingiu a distância máxima de forma homogênea, característica do microaspersor empregado.

Como era de se esperar, o sistema radicular das plantas de cítrus diminuiu com a profundidade, sendo que a maior concentração de radicelas ocorreu na camada superficial (0-10 $\mathrm{cm})$; porém, deve-se considerar que a redução foi significativa para a segunda e terceira profundidades avaliadas. Moreira (1988) observou que as radicelas de plantas de laranja-"Pêra", nos primeiros $15 \mathrm{~cm}$ do solo, representaram cerca de $45 \%$ das raízes, 
e $13 \%$ encontram-se a $15-30 \mathrm{~cm}$ de profundidade.

\section{CONCLUSÃO}

1 - Os teores de macro e micronutrientes nas folhas não foram alterados pela irrigação, pelos sistemas de fertirrigação e pela lâmina de água aplicada.

2 - $\mathrm{O}{ }^{\circ}$ Brix não foi adequado para expressar a diferença entre os tratamentos irrigados e destes com o sem irrigação.

3 - A acidez total titulável foi superior no tratamento sem irrigação. 4 - A \% de suco no fruto e "ratio" não foram afetadas pelos tratamentos com e sem irrigação.

5 - A massa fresca de raiz foi maior nos tratamentos irrigados em relação ao sem irrigação.

6 - Os sistemas de gotejamento e microaspersão não diferiram entre si quanto à massa de raízes.

7 - A maior concentração de raízes ocorreu até $30 \mathrm{~cm}$ do emissor e até $10 \mathrm{~cm}$ de profundidade.

\section{REFERÊNCIAS BIBLIOGRÁFICAS}

AVILÁN, L.R; MENESES, L; SUCRE, R. Comportamento del sistema radicular de patron cleopatra injertado com laranja "Valência" en suelos de textura fina. Agronomia Tropical, Maracay, v. 33, n.1/6, p. 155-170, 1982.

BATAGLIA, O.C; FURLANI, A.M.C; TEIXEIRA, J.P.F; FURLANI, P.R; GALO, J.R. Métodos de análise química de plantas. Circ. Téc. Tinst. Agron. Campinas, n. 87, p.1-31, 1983. BERNANDO, S. Manual de irrigação. 6. ed. Viçosa: UFV, Impr. Univ., 1995.657p.

BORKET, C.M. Manganês. In: FERREIRA, M. E; CRUZ, M.C.P. Micronutrientes na Agricultura. Piracicaba: Potafos, 1991.p. 173-88.

EMPRESA BRASILEIRA DE PESQUISA AGROPECUÁRIA Manual de métodos de análise de solo. 2 ed. Rio de Janeiro: CNPS/EMBRAPA, 1997.212p.

FAVETTA, G.M. Avanço e alternativas da irrigação no Brasil In: NAKAMAE, I.J. ; PASTRELlO, C.P. (Ed.) Agrianual 2001: Anuário da Agricultura Brasileira. São Paulo: Ed. Argos Comunicação, 2001.p. 545.

FIGUEIREDO, J.O. Variedades-copa de valor comercial. In: CITRICULTURA BRASILEIRA, 1., 1991. Campinas. Anais... Campinas: Fundação Cargill, 1991. p. 228-64.

GRUPO PAULISTA DE ADUBAÇÃO E CALAGEM PARA CITROS. Recomendação de adubação e calagem para cítrus no
Estado de São Paulo. Laranja Edição Especial, 27p., 1994. Corderópolis,

HALLMARK, W. B.; BARBER, S. A Root growth and of soybeans as affected by soil and morphology, nutrient uptake and nutrient status of early growth of soybeans as affected by soil P and K. Agronomy Journal, v. 76, p. 209-212, 1984.

HERNANDEZ, F. B. T. Potencialidades de fertirrigação, In: VITTI, G. C.; BOARETTO, A. E., coord. Fertilizantes fluídos, Piracicaba: POTAFOS, 1994. p. 215-225.

KHAN, A. A.; YITAYEW, M.; WARRICK, A W. Field evolution of water and solute distribution from a point source. Journal of Irrigation and Drainage Engineering, v.4, p. 221-227, 1996.

LEGAZ, F.; PRIMO-MILLO, E. Absorption and distribution of nitrogen-15 applied to young orange trees. In: INTERNATIONAL CITRUS CONGRESS, 6, 1988, Tel Aviv. Anais... Moncada: Instituto Valenciano de Investigaciones Agrarias, 1988. p. 643-61.

PACE, C.A.M.; ARAÚJO, C.M. Estudo da distribuição do sistema radicular de porta-enxertos cítricos em solos podzolizados e sua relação com a formação de copas. In: CONGRESSO BRASILEIRO DE FRUTICUlTURA, 8., 1986, Brasília. Anais... Brasília: EMBRAPA, CNPq, 1986, v.1, p. 199-205.

RAGOSO, C.R.A. Eficiência de aproveitamento de nutrientes em plantas cítricas quando aplicados via fertirrigação em comparação com a adubação convencional. 1999. 57f. Dissertação (Mestrado em Irrigação e Drenagem) - Faculdade de Ciências Agronômicas, Universidade Estadual Paulista, Botucatu, 1999.

RÊGO, I.C. Calagem e gessagem num Latossolo VermelhoEscuro cultivado com laranjeira-pêra, sobre limoeiro-cravo. 1997. 94f. Tese (Doutorado) - Centro de Energia Nuclear na Agricultura, Universidade de São Paulo, Piracicaba, 1997.

SILVA, M. M.; JUSTINO, O A Experiência prática no uso de fertilizantes fluídos em citros. In: VITTI, G. C.; BOARETTO, A . E. (Coord.) Fertilizantes fluidos. Piracicaba: POTAFOS, 1994. p. 179-187.

TENNANT, D. A., A test of a modified line interseat method of estimating root length. Journal Ecology, Oxford, v. 63 p. 995 1001, 1975.

ZANINI, J.R. Distribuição de água e de íon potássio no solo, aplicados por fertirrigação em gotejamento. I - Formação do bulbo molhado. Irrigação e Tecnologia Moderna, Brasília, n.45, p. 13-24, 1991. 